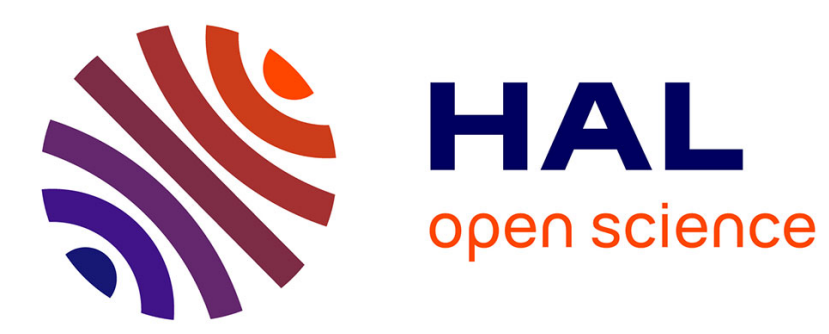

\title{
High-order sliding modes and intelligent PID controllers: First steps toward a practical comparison
}

Samer Riachy, Michel Fliess, Cédric Join

\section{To cite this version:}

Samer Riachy, Michel Fliess, Cédric Join. High-order sliding modes and intelligent PID controllers: First steps toward a practical comparison. 18th IFAC World Congress, IFAC WC'2011, Aug 2011, Milan, Italy. 10.3182/20110828-6-it-1002.01472 . hal-00580970v2

\section{HAL Id: hal-00580970 \\ https://hal-polytechnique.archives-ouvertes.fr/hal-00580970v2}

Submitted on 30 Mar 2021

HAL is a multi-disciplinary open access archive for the deposit and dissemination of scientific research documents, whether they are published or not. The documents may come from teaching and research institutions in France or abroad, or from public or private research centers.
L'archive ouverte pluridisciplinaire HAL, est destinée au dépôt et à la diffusion de documents scientifiques de niveau recherche, publiés ou non, émanant des établissements d'enseignement et de recherche français ou étrangers, des laboratoires publics ou privés. 


\title{
High-order sliding modes and intelligent PID controllers: First steps toward a practical comparison
}

\author{
Samer RIACHY ${ }^{*}$ Michel FLIESS ${ }^{* *}$ Cédric JOIN ${ }^{* * *}$ \\ * Non-A/INRIA \& ECS-Lab, EA 3649, ENSEA, 6 avenue du Ponceau, \\ 95014 Cergy-Pontoise, France. Samer.Riachy@ensea.fr \\ ** LIX (CNRS, UMR 7161) École polytechnique, 91128 Palaiseau, \\ France.Michel.Fliess@polytechnique.edu \\ *** Non-A/INRIA \& CRAN (CNRS, UMR 7039), Nancy-Université, \\ BP 239, 54506 Vandoeuvre-lès-Nancy, France. \\ Cedric.Join@cran.uhp-nancy.fr
}

\begin{abstract}
This communication is devoted to a "practical" comparison between high-order sliding modes and the recently introduced model-free control. The perfect knowledge of the relative degree of the output variable, which is a standard assumption for sliding modes, is assumed here. Our comparisons are based on two concrete case-studies and on numerous computer simulations. The smoothness of the input variables, the robustness with respect to noises and the straightforward extendibility of the model-free controllers to MIMO systems are highlighted.
\end{abstract}

Keywords: Nonlinear control; higher-order sliding mode control; model-free control; intelligent PIDs; online parameter estimation.

\section{INTRODUCTION}

The excellent robustness properties of sliding mode control with respect to perturbations and uncertainties explains its great popularity (see, e.g., Edwards \& Spurgeon [1998], Perruquetti \& Barbot [2002], Utkin [1992], Utkin et al. [1999]). Chattering, i.e., the high frequency commutations of the control variables, is however, as we know, a major drawback of this setting. Among the many works aimed at the attenuation of this most annoying shortcoming, let us mention High-Order Sliding Modes (see Levant \& Alelishvili [2008]), or HOSM, the boundary layer approach (Slotine [1991]) and the sliding sector method (Furuta et al. [2000]).

There exist several classes of HOSM algorithms (see, e.g., Levant [2005], Levant \& Alelishvili [2007, 2008] and the references therein) especially nested sliding modes, quasi-continuous controllers and high order integral sliding mode. The last category is particularly interesting to overcome the chattering effect by (artificially) raising the relative degree. An output feedback sliding mode controller can be realized by combining a sliding mode controller with a sliding mode differentiator. An interesting sliding mode controller for MIMO systems in Defoort et al. [2009] is based on the finite time stability of a chain of integrators from Bhat \& Bernstein [2005]. We mention that sliding mode controllers had led to a huge number of exciting applications involving real systems as in Bartolini et al. [2000, 2003], Ghanes et al. [2010], Khan et al. [2003], Levant et al. [2000], Defoort et al. [2009], Orlov et al. [2003], SiraRamírez [2002], Spurgeon et al. [2003], Shkolnikov et al.
[2000], Shkolnikov \& Shtessel [2002], Shtessel \& Shkolnikov [2003].

Model-free control (Fliess \& Join [2008, 2009], Fliess et al. [2011a]) is a recently introduced approach, which does not necessitate any mathematical modeling. The unknown dynamics is approximated on a very small time interval by a very simple model which is continuously updated with the aid of online estimation techniques (Fliess \& Sira-Ramírez [2003, 2008]). The loop is closed thanks to an intelligent PID, which provides the feedforward compensation and is easily tuned. Model-free control has already led to a number of exciting applications. ${ }^{1}$

Since the knowledge of the relative degree is a standard assumption in sliding mode control, ${ }^{2}$ we deal in this article with SISO minimum phase systems of the form

$$
\begin{aligned}
& \dot{x}=a(x)+b(x) u, \quad x \in \mathcal{D} \subset \mathbb{R}^{n}, u \in \mathbb{R} \\
& y=s(x)
\end{aligned}
$$

where $n$ and the smooth functions $a, b$ and $s$ are unknown while the relative degree $r$ of $y$ is constant and known:

$$
y^{(r)}=f(x)+g(x) u \text {. }
$$

With the classical assumption $g(x) \neq 0$ and the knowledge of bounds on $f$ and $g$, all HOSM controllers listed above solves the problem of zeroing the output $y$ in finite time. If the relative degree is not artificially raised, chattering appears when the output and its derivatives up to order $r-1$ are close to 0 . The output $y$ can be chosen to solve

\footnotetext{
1 See the references in Fliess et al. [2011a,b].

2 With the exception of some recent works (see, e.g., Levant [2010] and the references therein).
} 
a stabilization or a trajectory tracking problem. We show how model-free control can be adapted to the particular situation of (1)-(2).

The knowledge of $r$ is not a restrictive assumption for a large number of finite-dimensional systems encountered in practice: robotic manipulators, mobile robots, electric drives, for example, are modeled by a collection of nonlinear integrators, which may be simple or double. Moreover, dynamic models may be automatically generated by symbolic softwares (see, e.g., Khalil \& Creusot [1997] for robotic manipulators). The identification of physical parameters involved in such models is nevertheless a difficult task. Both sliding modes as well as model-free controllers aim to bypass this last step.

The comparison between sliding modes and model-free control is kept here at a practical level for the following two reasons:

- The mathematical backgrounds are different:

- differential inclusions for sliding modes,

- various algebraic tools for model-free control.

- In the presence of unavoidable noise corruptions the concepts of finite-time and asymptotic stabilities boil both down to "practical" stability.

Our paper is organized as follows. After a short review of model-free control in Section 2, Section 3 defines, via online algebraic estimation techniques, a new controller which takes into account the knowledge of the relative degree. Two nonlinear case-studies are analyzed in Section 4, where numerous computer simulations are displayed. Some concluding remarks are provided in Section 5.

\section{A SHORT REVIEW OF MODEL-FREE CONTROL}

\subsection{Generalities}

Replace the unknown, or at least poorly known, system equation by the "ultra-local" model ${ }^{3}$

$$
y^{(\nu)}(t)=F(t)+\alpha u(t)
$$

which is continuously updated, where

- the constant coefficient $\alpha$ is chosen by the practitioner, such that $\alpha u$ and $y^{(\nu)}$ are of the same order of magnitude;

- the time-varying function $F(t)$, which is estimated thanks to the knowledge of $u$ and $y$, subsumes the structural properties;

- the order $\nu$ of derivation is always $\leq 2$.

The loop may be closed, if $\nu=1$ for example, via an intelligent PI controller, or i-PI,

$$
u=-\frac{F}{\alpha}+\frac{\dot{y}^{\star}}{\alpha}+K_{P} e+K_{I} \int e
$$

where $y^{\star}$ is the output reference trajectory, $e=y-y^{\star}$ is the tracking error, $K_{P}, K_{I}$ are the usual PI gains.

\subsection{Identification and estimation issues}

Consider

$$
L\left(\frac{d}{d t}\right) z=\phi+\alpha u
$$

\footnotetext{
3 See in the same proceedings Fliess et al. [2011b] and the references therein for more details.
}

where

- $\phi$ and $\alpha$ are unknown constants,

- $L\left(\frac{d}{d t}\right) \in \mathbb{R}\left[\frac{d}{d t}\right]$ is a linear differential operator with constant coefficients,

- $\frac{d^{\nu} z}{d t^{\nu}}=y$ for some $\nu \geq 0$.

We thus approximate an unknown function like $F$ in Equation (3) by a piecewise constant one. The above equation reads in the operational domain:

$$
L(s) Z=\frac{\phi}{s}+\alpha U+I(s)
$$

where $I \in \mathbb{R}[s]$ is a polynomial associated to the initial conditions. For $N \geq 1$ sufficiently large, $\frac{d^{N} I}{d s^{N}} \equiv 0$. Multiplying both sides of equation (5) by $\frac{d^{N}}{d s^{N}}$ permits to get rid of the initial conditions.

$$
\frac{d^{N}}{d s^{N}} L(s) Z=\frac{(-1)^{N} N !}{s^{N+1}} \phi+\alpha \frac{d^{N} U}{d s^{N}}
$$

Rewriting Equation (6) with $N_{1} \neq N$ yields the linear identifiability (Fliess \& Sira-Ramírez [2003, 2008]) of $\phi$ and $\alpha$. Multiplying both sides of Equations (6) by $s^{-M}$, where $M \geq 0$ is sufficiently large, permits to get rid of positive powers of $s$, i.e., of derivatives with respect to time. The corresponding formulae in the time domain are easily deduced thanks to the correspondence between $\frac{d}{d s}$ and the multiplication by $-t$ in the time domain. Note that the above computations together with the sampling provides a linear discrete filter which is easily implemented for real time applications.

Remark 1. See also Michel [2010] for another approach of the estimation of $\alpha$.

\section{SYNTHESIZING THE CONTROLLER WITH THE KNOWLEDGE OF THE RELATIVE DEGREE}

Rewrite Equation (2) as follows:

$$
y^{(r)}(t)+\sum_{i=-m}^{r-1} a_{i} y^{(i)}(t)=h(x, t)+g(x) u(t)
$$

where $h(x, t)=f(x)+\sum_{i=-m}^{r-1} a_{i} y^{(i)}, m \in \mathbb{N}, y^{(-m)}=$ $\underbrace{\int \cdots \int}_{m} y$. The left hand side of Equation (7) is a Hurwitz polynomial, which is related to an obvious stabilization procedure.

Apply the techniques sketched in Section 2.2 in order to obtain estimates of piecewise constant approximations $F$ and $\alpha$ of $h$ and $g$ in Equation (7). ${ }^{4}$ Then

$$
u=-\frac{F}{\alpha}
$$

defines a stabilizing controller.

\section{NUMERICAL SIMULATIONS}

The two systems below are flat (Fliess et al. [1995], Lévine [2009], Sira-Ramírez et al. [2004]). We know moreover

\footnotetext{
4 A lack of space prevents us from reproducing detailed calculations, which show that a rough estimate of $g$ is sufficient.
} 
that flatness-based control provides a most efficient control strategy. Let us therefore emphasize again that our only aim here is a comparison between sliding modes and model-free control.

\subsection{A kinematic car model}

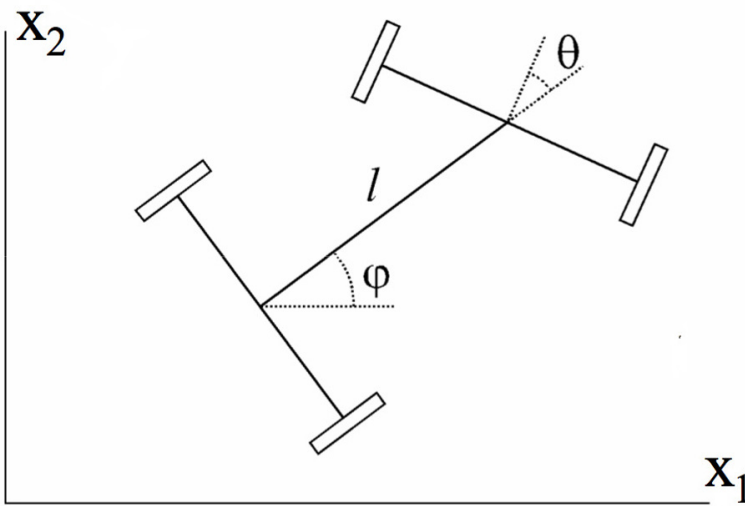

Fig. 1. A car in Cartesian coordinates

The kinematic car model, which is borrowed from Levant \& Alelishvili [2008], is depicted in Figure 1. It satisfies the following equations:

$$
\begin{gathered}
\dot{x}_{1}=v \cos \varphi \quad \dot{x}_{2}=v \sin \varphi, \\
\dot{\varphi}=\frac{v}{l} \tan \theta \quad \dot{\theta}=u
\end{gathered}
$$

The variables $x_{1}$ and $x_{2}$ represent the Cartesian coordinates of the rear-axle middle point, ${ }^{5} \varphi$ is the orientation angle, while $v$ is the longitudinal velocity. The parameter $l$ measures the distance between the two axles and $\theta$ is the steering angle. The control task is to drive the car toward a reference trajectory of the form $x_{2}=\bar{g}\left(x_{1}\right)$ where $x_{1}$ and $x_{2}$, i.e. $\bar{g}\left(x_{1}\right)$, are measured. Let $y=s\left(x_{1}, x_{2}\right)=x_{2}-\bar{g}\left(x_{1}\right)$, $v=10 \mathrm{~m} / \mathrm{s}, l=5 \mathrm{~m}, \bar{g}\left(x_{1}\right)=10 \sin \left(0.05 x_{1}\right)+5$. Initial conditions are set to 0. Levant \& Alelishvili [2008] utilizes the following controller:

$$
u=-\frac{z_{2}+2\left(\left|z_{1}\right|+\left|z_{0}\right|^{2 / 3}\right)^{-1 / 2}\left(z_{1}+\left|z_{0}\right|^{2 / 3} \operatorname{sign}\left(z_{0}\right)\right)}{\left|z_{2}\right|+2\left(\left|z_{1}\right|+\left|z_{0}\right|^{2 / 3}\right)^{1 / 2}} .
$$

The variables $z_{0}, z_{1}$ and $z_{2}$ are respectively the filtered values of the noisy output $y$ and of its derivatives of first and second orders. They are the outputs of the following second order differentiator:

$$
\begin{aligned}
& \dot{z}_{0}=\nu_{0}, \quad \nu_{0}=-14.7361\left|z_{0}-\sigma\right|^{2 / 3} \operatorname{sign}\left(z_{0}-\sigma\right)+z_{1}, \\
& \dot{z}_{1}=\nu_{1}, \quad \nu_{1}=-30\left|z_{1}-\nu_{0}\right|^{1 / 2} \operatorname{sign}\left(z_{1}-\nu_{0}\right)+z_{2} \\
& \dot{z}_{2}=-440 \operatorname{sign}\left(z_{2}-\nu_{1}\right) .
\end{aligned}
$$

As indicated in Levant \& Alelishvili [2008], a step sampling of 0.0001 second is used to simulate the sliding mode control using the Euler method.

Set, for implementing our model-free control, $m=0$ and $r=3$ in Equation (7). The parameters $a_{0}, a_{1}$ and $a_{2}$ of

5 Remember that this middle point is a flat output (Fliess et al. [1995], Lévine [2009], Sira-Ramírez et al. [2004]).
Equation (7) are chosen according to a classical third order dynamics $(s-a)\left(s^{2}+2 \xi \omega_{n} s+\omega_{n}^{2}\right)=0$.

Simulation with a Brownian noise. Consider first that the measurements of $x_{1}$ and $x_{2}$ are altered by an additive Brownian noise ${ }^{6}$ a realization of which is shown in the Figure 2. According to Figure 3 model-free control provides better tracking performances. Moreover, the control inputs depicted in the Figures 4 and 5 show that the modelfree control input is smoother. Softer steering angle is also provided by the model-free controller (see Figures 6 and 7)

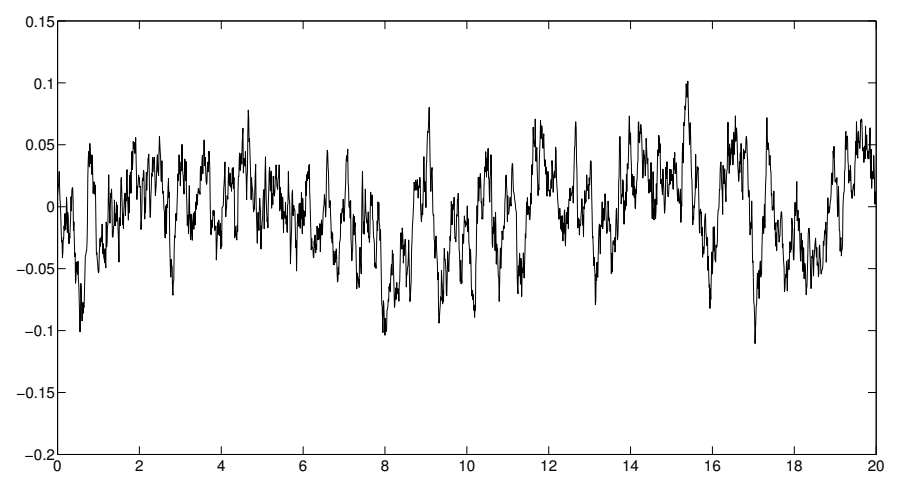

Fig. 2. Brownian noise realization used in the simulations

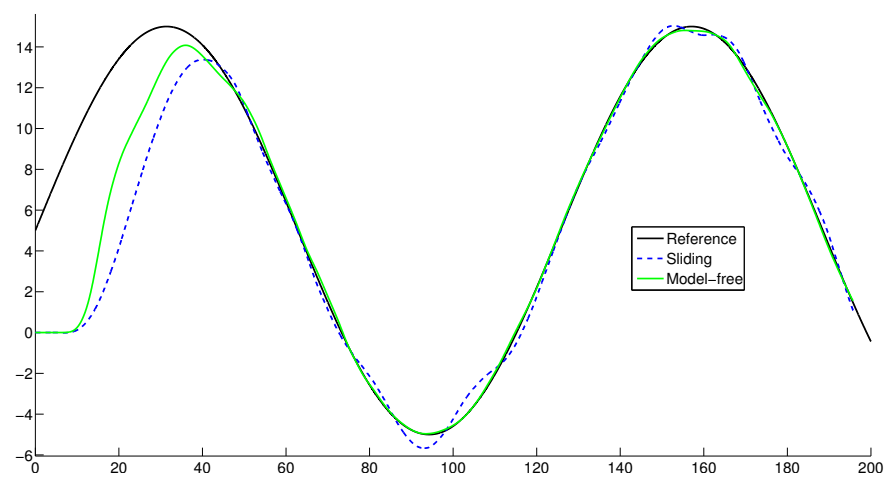

Fig. 3. Output tracking for both sliding mode and i-PID controllers

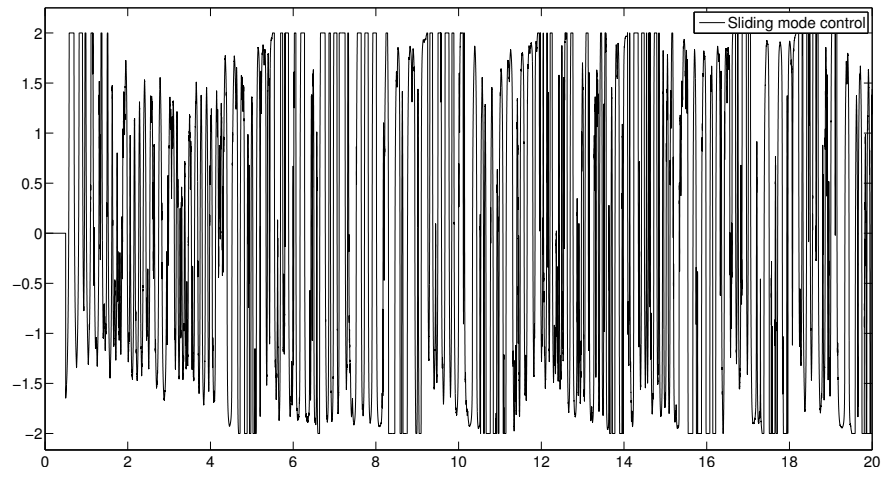

Fig. 4. Sliding mode control input

6 A Brownian noise is the integral of a Gaussian white noise. In the simulation, we used a low-pass filtered band-limited Gaussian white noise. 


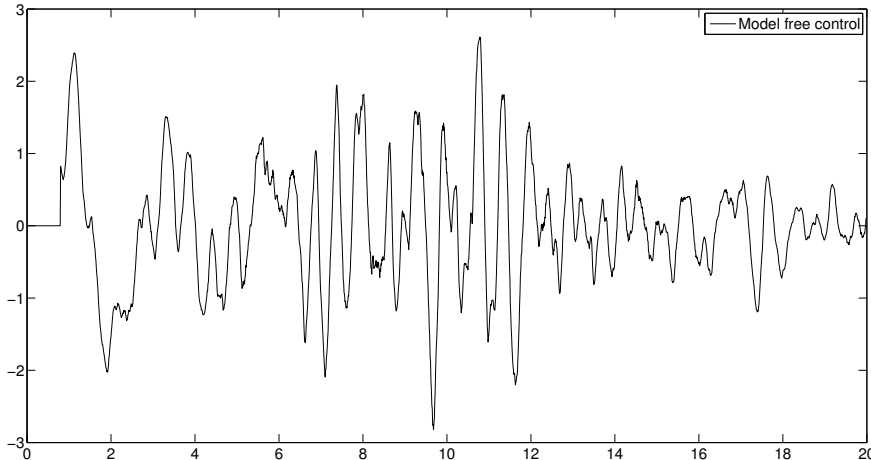

Fig. 5. Model-free control input

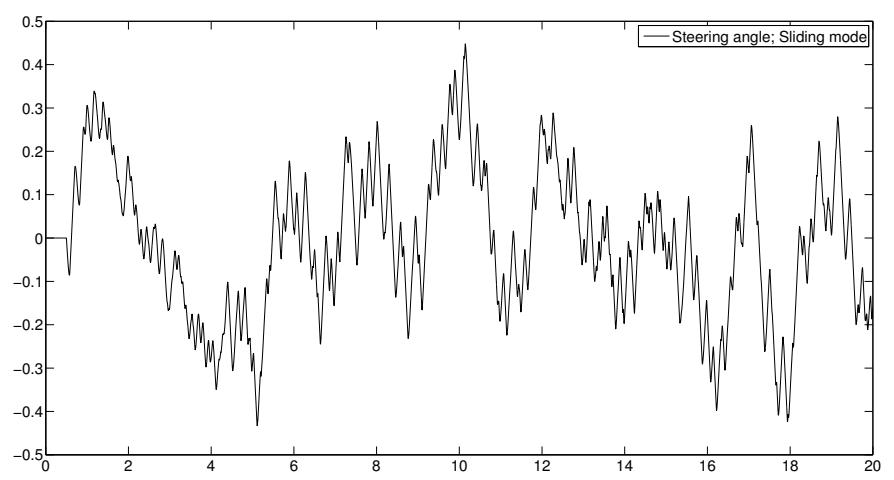

Fig. 6. Steering angle $\theta$ corresponding to the sliding mode controller

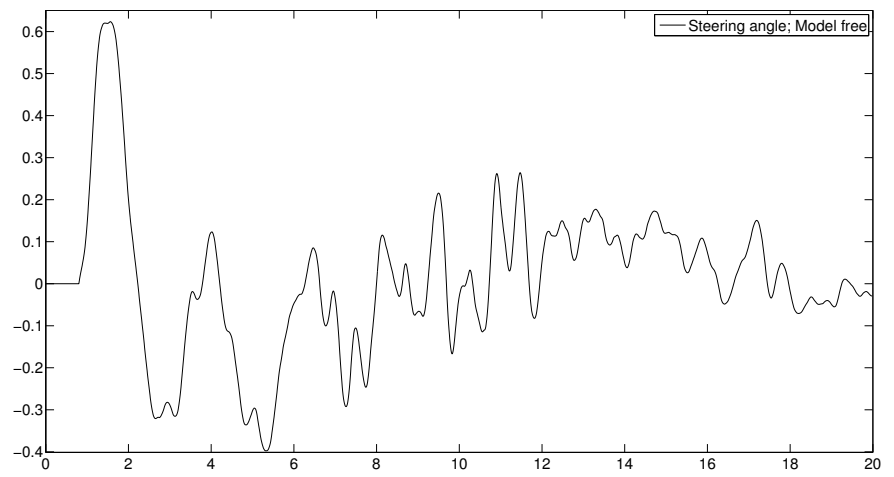

Fig. 7. Steering angle $\theta$ corresponding to the model-free controller

Simulation with a Gaussian white noise. Simulations with a zero-mean additive (band-limited) white noise of variance of 0.2 , are depicted in the Figures 8,9 and 10. They also show that the model-free controller performances are better: we achieve a better tracking without any chattering.

Remark 2. The chattering in Figure (4) can be eliminated by raising the relative degree. It would have complicated both the controller as well as the differentiator design. A well known solution is to consider $\dot{u}$ as a virtual input.

Remark 3. We took care to tune the parameters such that the control magnitudes of Figures 9 and 10 are similar. Compare also Figures 4 and 5 .

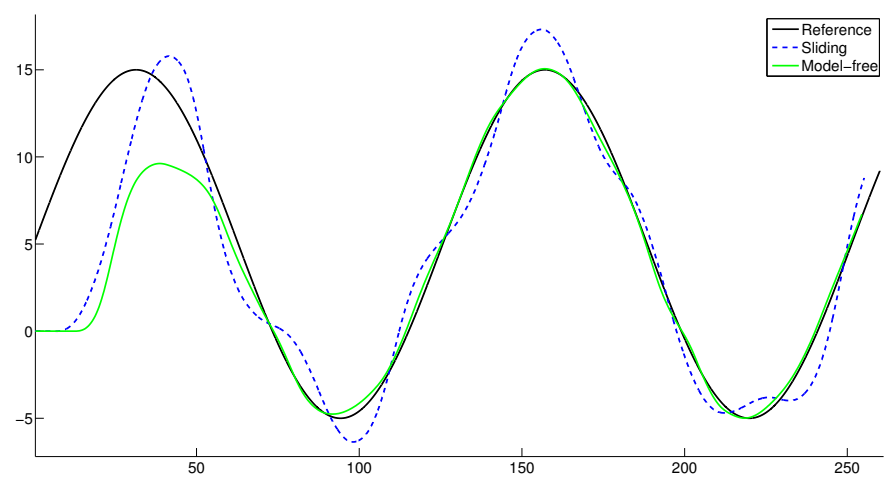

Fig. 8. Output tracking for both sliding mode and i-PID controllers

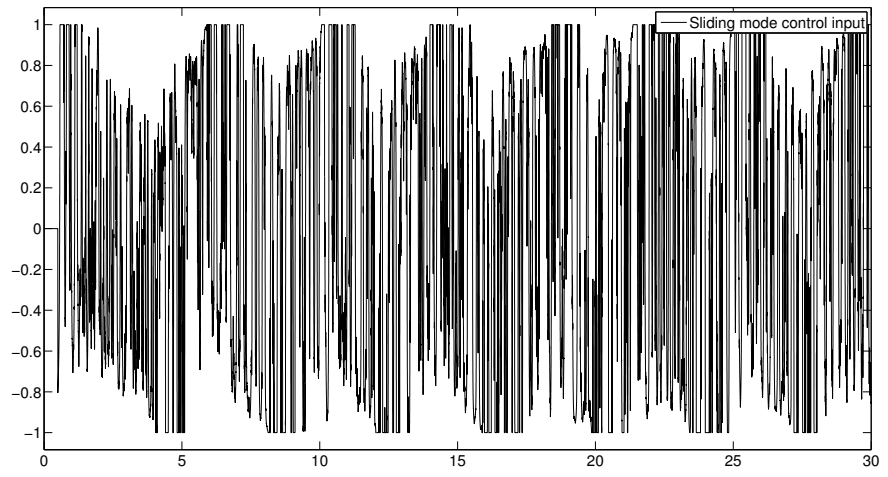

Fig. 9. Sliding mode control input

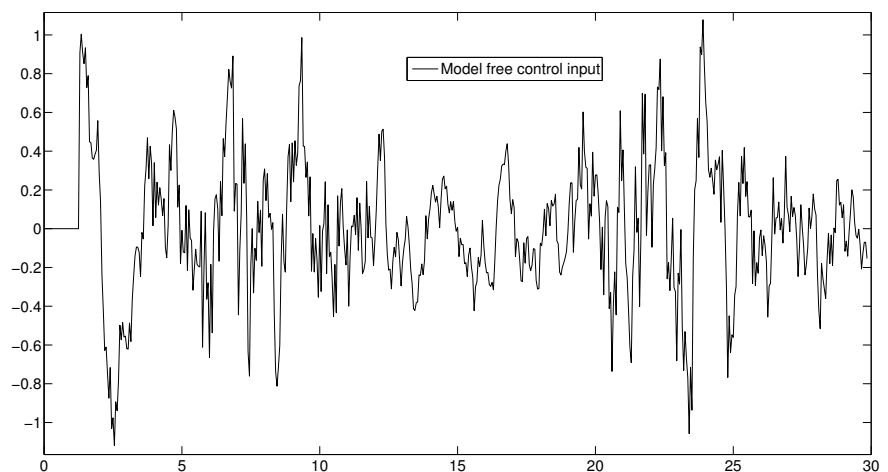

Fig. 10. Model-free control

\subsection{A three axis robot}

Figure (11) depicts a robotic manipulator with 3 arms and 3 input torques. It satisfies the equation

$$
\ddot{q}=M(q)^{-1}(G(q)+H(\dot{q}, q)+u)
$$

where $q=\left[q_{1}, q_{2}, q_{3}\right]^{T}, M(q)$ is the symmetric inertia matrix, $u=\left[u_{1}, u_{2}, u_{3}\right]^{T}$ are the control torques. We force the robot's end effector to draw a circle in a horizontal plane with constant angular velocity. It yields the reference trajectories $q_{1}^{\star}=2 \pi t$ while $q_{2}^{\star}$ and $q_{3}^{\star}$ are constant. Take for this purpose the model-free controller $\ddot{e}+K_{d} \dot{e}+K_{P} e=$ $F(t)+\alpha u$, where $m=0$ and $r=2, \alpha$ is a $3 \times 3$ matrix, and $e=q-q^{\star}$. Figures 12, 13, 14, 15 and 16 illustrates the effectiveness of the straightforward controller $u=\alpha^{-1} F$.

Remark 4. Extending model-free control to some MIMO systems is straightforward. It does not seem to be the case for sliding modes. 


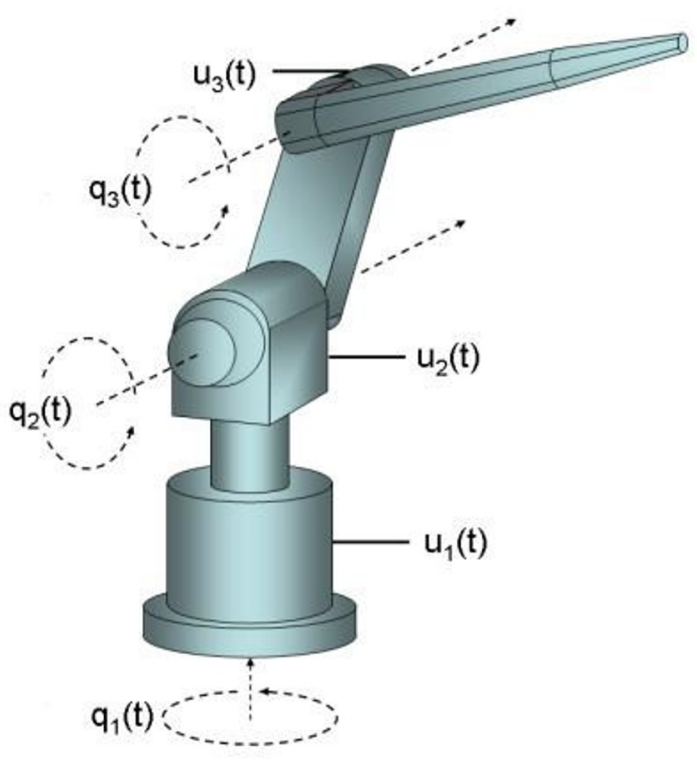

Fig. 11. Manutec R3 robot

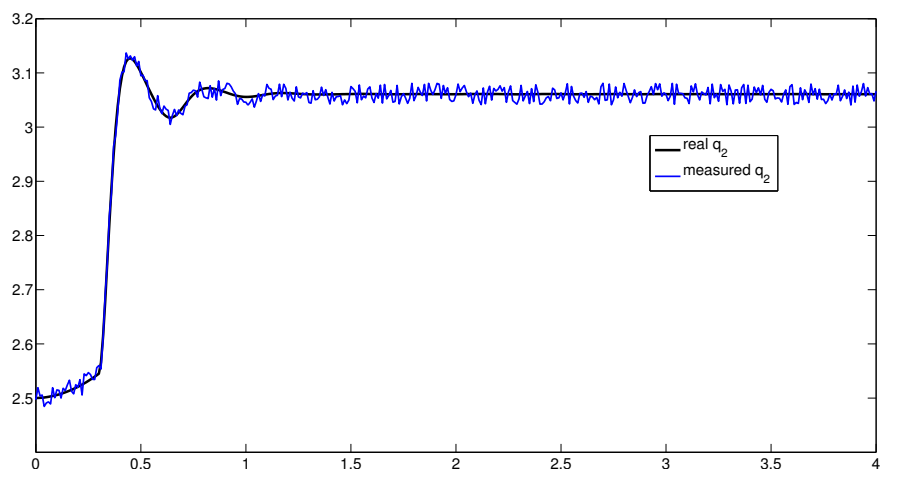

Fig. 12. Real and measured variable $q_{2}$.

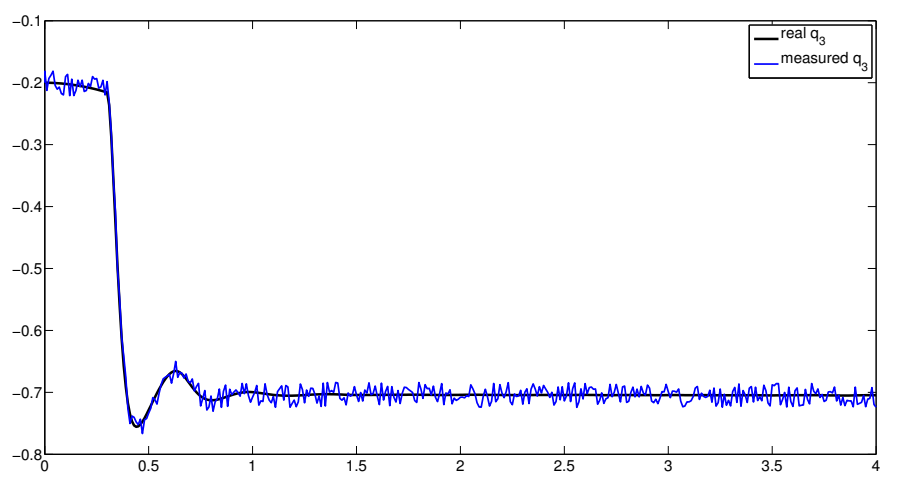

Fig. 13. Real and measured variable $q_{3}$.

\section{CONCLUSION}

Our two case-studies lead to the following observations, which need further theoretical and practical investigations in order to be fully confirmed:

- The model-free controllers yield smooth control variable, without any chattering.

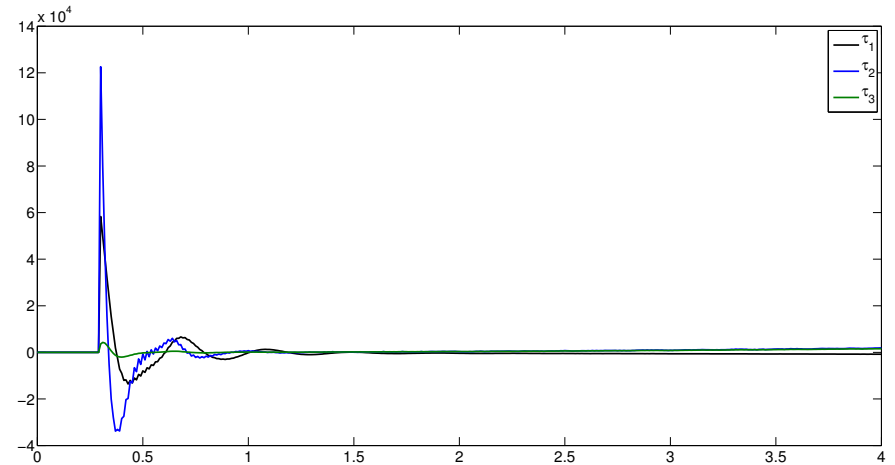

Fig. 14. Control inputs.

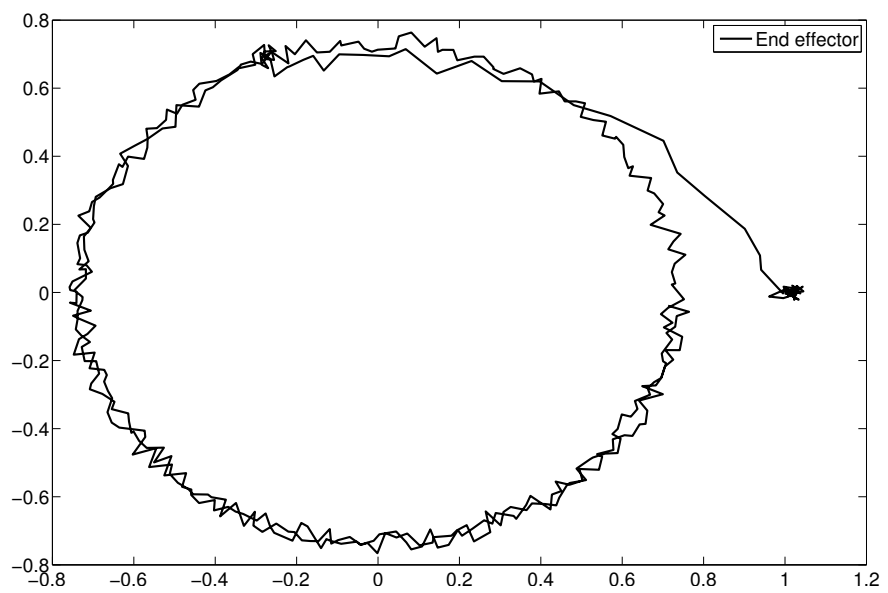

Fig. 15. Measured robot's end effector position (circular trajectory).

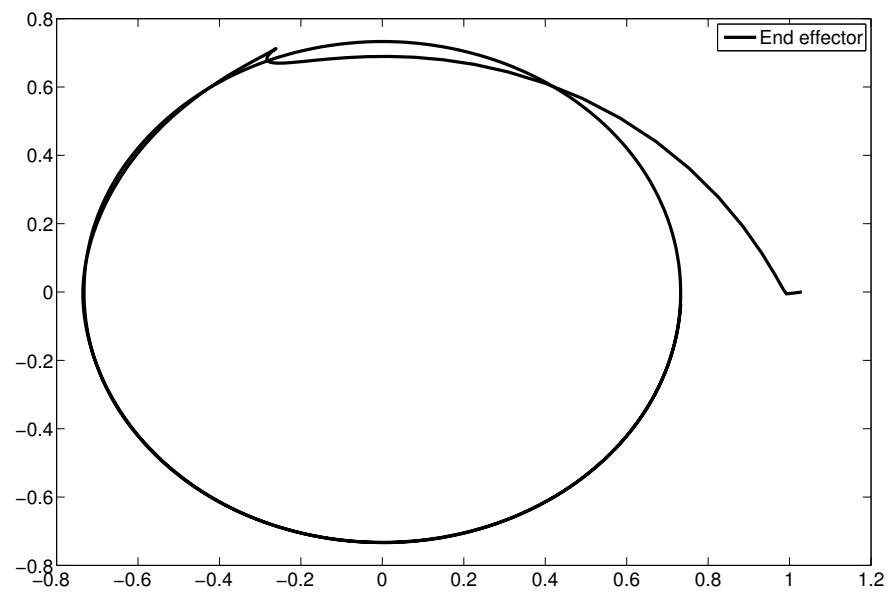

Fig. 16. Real (noise-free) robot's end effector position (circular trajectory).

- The implementation of model-free control only necessitates a standard discrete linear filter, whereas a rather complex derivation of noisy signals is used for sliding modes, where, moreover, the calculation of fractional powers is quite demanding.

- The choice of the model-free controller parameters is obvious.

- The model-free controller seem to be more robust with respect to corrupting noises.

- It is straightforward to extend model-free control to some MIMO systems. 


\section{REFERENCES}

G. Bartolini, A. Ferrara, E. Punta Multi-input secondorder sliding-mode hybrid control of constrained manipulators. Dynamics Control., volume 10, pages 277-296, 2000.

G. Bartolini, A. Pisano, E. Punta, E. Usai. A survey of applications of second order sliding mode control to mechanical systems. Int. J. Contr., volume 76, pages $875-892,2003$.

S. Bhat, D. Bernstein. Geometric homogeneity with application to finite time stability. Math. Control Signals Systems, volume 17, pages 101-127, 2005.

S. C. Chung, C.-L. Lin. A general class of sliding surface for sliding mode control. IEEE Trans. Automat. Control, volume 43, pages 115-119, 1998 .

M. Defoort, T. Floquet, A. Kokosy, W. Perruquetti. A novel higher order sliding mode control strategy. Syst. Control Lett., volume 58, pages 102-108, 2009.

M. Defoort, T. Floquet, A. Kokosy, W. Perruquetti. Sliding mode control of cooperative autonomous mobile robots. IEEE Trans. Industrial Electron., volume 55 , pages 439-467, 2009.

B. Drazenovic. The invariance conditions in variable structure systems. Automatica, volume 5, pages 287 295, 1969.

C. Edwards, S.K. Spurgeon. Sliding Mode Control Theory and Applications. Taylor \& Francis, 1998.

A. Estrada, L. Fridman. Quasi-continuous HOSM control for systems with unmatched perturbations Internat. Workshop Variable Structure System, Antalya, 2008.

A. Estrada, L. Fridman. Quasi-continuous HOSM Control for systems with unmatched perturbations. Automatica, volume 46, pages 1916-1919, 2010.

M. Fliess, C. Join. Commande sans modèle et commande à modèle restreint. $e-S T A$, volume $5\left(\mathrm{n}^{\circ} 4\right)$, pages $1-23$, 2008.

M. Fliess, C. Join. Model free control and intelligent PID controllers: towards a possible trivialization of nonlinear control? $15^{\text {th }}$ IFAC Symp. System Identif., Saint-Malo, 2009.

M. Fliess, C. Join, S. Riachy. Rien de plus utile qu'une bonne théorie: la commande sans modèle. JN-JDMACS, Marseille, 2011a.

M. Fliess, C. Join, S. Riachy. Revisiting some practical issues in the implementation of model-free control. IFAC World Congress, Milan, 2011b.

M. Fliess, J. Lévine, P. Martin, P. Rouchon. Flatness and defect of non-linear systems: introductory theory and examples. Int. J. Control, volume 61, pages 1327-1361, 1995.

M. Fliess, H. Sira-Ramírez. An algebraic framework for linear identification. ESAIM Control Optimiz. Calc. Variat., volume 9, pages 151-168, 2003.

M. Fliess, H. Sira-Ramírez. Closed-loop parametric identification for continuous-time linear systems via new algebraic techniques. In H. Garnier \& L. Wang (Eds): Identification of Continuous-time Models from Sampled Data, pages 362-391, 2008.

K. Furuta, Y. Pan. Variable structure control with sliding sector. Automatica, volume 36, pages 211-228, 2000.

M. Ghanes, J.-P. Barbot, J. De Leon, A. Glumineau. A robust sensorless output feedback of the induction motor: New design and experimental validation. Int. J.
Control, volume 83, pages 484-497, 2010.

W. Khalil and D. Creusot. SYMORO+: a system for the symbolic modelling of robots. Robotica, volume 15, pages 153-161, 1997.

M.K. Khan, K.B. Goh, S.K. Spurgeon. Second order sliding mode control of a diesel engine. Asian J. Control, volume 5, pages 614-619, 2003.

A. Levant. Quasi-continuous high-order sliding mode controllers. IEEE Trans. Automat. Control, volume 50, pages 1812-1816, 2005.

A. Levant. Finite-time stability and high relative degree in sliding-mode control. Internat. Workshop Variable Structure Systems, Mexico, 2010.

A. Levant, L. Alelishvili. Integral high-order sliding modes. IEEE Trans. Automat. Control, volume 52, pages 1278$1282,2007$.

A. Levant, L. Alelishvili. Discontinuous homogeneous control. In G. Bartolini et al. (Eds.): Modern sliding Mode Control Theory, LNCIS 375, Springer, pages 7195, 2008.

A. Levant, A. Pridor, R. Gitizadeh, I. Yaesh, J.Z. BenAsher. Aircraft pitch control via second-order siding techniques. J. Guidance Control Dynamics, volume 23, pages 586-594, 2000.

J. Lévine. Analysis and Control of Nonlinear Systems - A Flatness-based Approach. Springer, 2009.

L. Michel. Variational and symplectic approach of the model-free control. Manuscript available at http://arxiv.org/abs/1011.4237, 2010.

Y. Orlov, L. Aguillar, J.C. Cadiou. Switched chattering control vs. backlash/friction phenomena in electrical servo-motors. Int. J. Contr., volume 76, pages 959-967, 2003.

W. Perruquetti, J.-P. Barbot (Eds). Sliding Mode Control in Engineering. Marcel Dekker, 2002.

H. Sira-Ramírez. Dynamic second order sliding mode control of the hovercraft vessel. IEEE Trans. Contr. Syst. Tech., volume 10, pages 860-865, 2002.

H. Sira-Ramírez, S. Agrawal. Differentially Flat Systems. Marcel Dekker, 2004.

J.-J. Slotine. Applied Nonlinear Control. Prentice-Hall, 1991.

S. Spurgeon, K.B. Goh, N.B. Jones. High-order sliding mode control of a diesel set. J. Systems Control Engineering, volume 50, pages 229-241, 2003.

I.A. Shkolnikov, Y.B. Shtessel, D. Lianos, A.T. Thies. Robust missile autopilot design via high-order lsiding mode control. Proc. AIAA Guidance Navigation Control Conf., Denver, 2000.

I.A. Shkolnikov, Y.B. Shtessel. Tracking in a class of nonminimum-phase systems with nonlinear internal dynamics via sliding mode control using method of system center. Automatica, volume 38, pages 837-842, 2002.

Y.B. Shtessel, I.A. Shkolnikov. Aeronautical and space vehicle control in dynamic sliding manifolds. Int. J. Contr., volume 76, pages 1000-1017, 2003.

V.I. Utkin. Sliding Modes in Optimization and Control. Springer, 1992.

V.I. Utkin, J. Guldner, J. Shi. Sliding Mode Control in Electro-Mechanical Systems. Taylor \& Francis, 1999. 